\title{
Análise dos quinze anos do periódico Perspectivas em Ciência da Informação
}

\author{
Carlos Alberto Ávila Araújo
}

Professor da Escola de Ciência da Informação da UFMG.

Marlene Oliveira Teixeira de Melo

Professora da Escola de Ciência da Informação da UFMG.

O artigo apresenta os resultados de um estudo bibliométrico sobre os volumes que compõem os primeiros quinze anos do periódico Perspectivas em Ciência da Informação, editado pela Escola de Ciência da Informação da UFMG. Foram analisados dados dos autores dos artigos (freqüência e vinculação institucional), das palavras-chave dos artigos e das referências dos artigos (autores citados, periódicos citados, tipologia, idioma e idade da literatura citada). Entre os principais resultados encontrados destacam-se que foram identificados 424 autores, com uma fraca concentração da produção (os 20 mais produtivos respondem por 85 artigos, um pouco menos de um sexto do total). Os autores que mais publicaram foram ou são vinculados à UFMG. Sobre as 4965 referências encontradas, verificouse que os autores mais citados foram Eco, Choo, Lancaster, Mueller, Drucker e Capurro. O idioma mais freqüente das referências é o português, a tipologia mais encontrada é o livro e o periódico mais citado é a revista Ciência da Informação. Alguns dos resultados encontrados foram confrontados com aqueles relativos a um estudo semelhante sobre a extinta Revista de Escola de Biblioteconomia da UFMG, que veio a ser substituída pelo periódico Perspectivas em Ciência da Informação.

Palavras-chave: Perspectivas em Ciência da Informação; Bibliometria; Análise de citações. 


\section{Introdução}

A revista Perspectivas em Ciência da Informação (PCI) completou em 2010 quinze anos de existência. Como parte das comemorações desta data, pensou-se, ainda em meados de 2010, na possibilidade de realização de um mapeamento da produção científica veiculada nela, de forma semelhante ao que foi feito com a extinta Revista da Escola de Biblioteconomia da UFMG (ARAúJO et al, 2010), isto é, um estudo bibliométrico que incidisse sobre toda a coleção, bem como um estudo bibliométrico amplo relativo aos diversos aspectos da produção científica veiculada pela revista: os autores que mais publicaram, os autores e periódicos mais citados, a idade e a tipologia a literatura citada, entre outros. Com o objetivo de suprir essa lacuna foi encomendado pelo Conselho Editorial da revista aos autores a realização da presente pesquisa, que contou ainda com a colaboração, para a coleta de sistematização dos dados, de alguns alunos do mestrado e doutorado em Ciência da Informação da ECI/UFMG.

Assim, além de contemplar a importância do objeto empírico em questão - a revista Perspectivas em Ciência da Informação - este artigo se insere na tendência contemporânea de trabalhos na área de Bibliometria e Cienciometria que têm enfatizado a importância da contribuição dos indicadores bibliométricos e cienciométricos para mapeamentos epistemológicos da produção científica de determinada área, fornecendo importantes dados sobre a forma como essa produção científica tem sido construída (COSTA; VANZ, 2010; SANTOS et al, 2007; VANTI, 2002). Para tanto, busca-se realizar um estudo bibliométrico explorando várias das possibilidades abertas com esse tipo de estudo (ARAÚJO, 2006; BRAMBILLA; VANZ; STUMPF, 2006), como aliás vem sendo historicamente proposto por esse campo de estudos desde suas origens (FIGUEIREDO, 1977; ROUSSEAU, 1998; RODRIGUES, 1981; FORESTI, 1989).

A revista Perspectivas em Ciência da Informação nasceu em 1996, em substituição à Revista da Escola de Biblioteconomia, como parte do amplo espectro de mudanças que resultou também na mudança do nome do mestrado (de Biblioteconomia para Ciência da Informação), das grades curriculares dos cursos de graduação em Biblioteconomia e de pósgraduação em Ciência da Informação, e ainda, posteriormente, no próprio nome da escola (que passou a se chamar Escola de Ciência da Informação), seguindo uma tendência verificada em nível internacional. Recentemente, com a criação dos cursos de graduação em Arquivologia e Museologia, completou-se o amplo processo de construção do campo científico abarcado pela instituição que sedia esta revista - a ECI/UFMG.

Ao longo de sua evolução, Perspectivas em Ciência da Informação caracterizou-se pela regularidade, pelo compromisso com a qualidade dos artigos publicados, pela correção e rigor editorial, bem como pela diversidade temática dos conteúdos e de procedência institucional dos autores. Começando como periódico impresso, durante alguns anos foi publicada também em formato eletrônico, sendo recentemente publicada 
exclusivamente em meio digital. Em 2011, como parte das comemorações do sucesso da revista, ela passou a ter periodicidade trimestral - o primeiro periódico nacional da área a conseguir tal feito.

\section{Resultados da análise bibliométrica}

A primeira parte da pesquisa consistiu no levantamento de todos os artigos publicados em todos os volumes publicados. Foram encontrados, em todo o período, xx artigos. Estes artigos foram analisados da seguinte forma: em termos de autoria, analisou-se os autores dos artigos e a instituição de pertencimento dos autores; em termos de temática, foram contabilizadas as palavras-chave; em termos das referências, os autores citados, os periódicos citados, idade e tipologia dos documentos citados.

\subsection{Sobre os autores dos artigos}

Para a contabilização dos autores dos artigos, o primeiro desafio encontrado foi interpretar os casos de co-autoria. Considerando-se as diversas opções apresentadas pelas técnicas bibliométricas (ARAÚJO, 2006), optou-se pela contagem absoluta de autoria, isto é, no caso de um artigo produzido por dois ou mais pesquisadores, atribuiu-se uma freqüência para cada um. Foram encontrados 424 autores que produziram 551 artigos publicados em PCI, com índices de produção variados. Um total de 354 autores publicaram apenas um artigo no período analisado, correspondendo a $83,49 \%$ do total de autores e $64,24 \%$ da produção. Com dois artigos, foram encontrados 38 autores e, com três, dezenove autores. Juntos, estes autores que publicaram até três artigos publicaram um total de 487 artigos, o que corresponde a 88,38\% do total. Foram encontrados 13 autores que produziram quatro ou mais artigos, e eles são apresentados a seguir:

GRÁFICO 1 - Autores mais produtivos na PCI

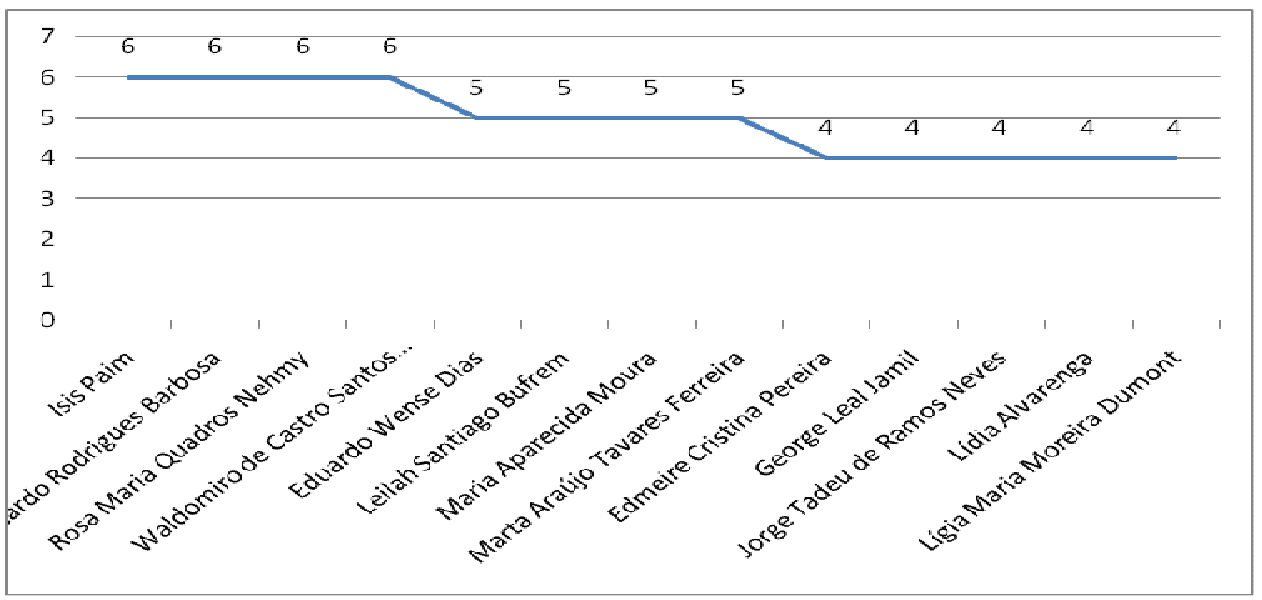

Fonte: Dados da pesquisa.

O Gráfico acima permite evidenciar que existe uma baixa concentração da produção. Caso se aplique a lei do elitismo de Price 
(ARAÚJO, 2006), que prevê um percentual de metade da produção para uma elite formada pela raiz quadrada do total de autores, teríamos 20 autores que produziram, juntos, 85 artigos - 15,42\%, ou seja, um valor bem menor do que aquele determinado para uma elite muito produtiva. Os casos de co-autoria não foram contabilizados, nem para os autores que mais publicaram, nem para os demais. Assim, a concentração afinal é mais baixa do que o comumente encontrado na produção científica.

Pode-se notar ainda que quase todos os autores mais produtivos são ou foram professores da própria Escola de Ciência da Informação (antiga Escola de Biblioteconomia) da UFMG. Se, com os padrões atuais, tal fato poderia ser interpretado como sinônimo de endogenia, cumpre lembrar que, desde o período em que a revista era publicada como REB (de 1972 a 1995) prevalecia, para os periódicos científicos, uma outra regra: a de que a função de um periódico científico era espelhar o pensamento do lugar em que era editado. Assim, incentiva-se que os próprios pesquisadores e professores do local em que era publicado determinado periódico publicassem neste periódico. A revista PCI nasceu ainda neste espírito, tanto que, no seu início, muito se incentivou que o próprio corpo docente da escola, e também o corpo discente, publicassem trabalhos sobretudo para ajudar na definição da própria Ciência da Informação como campo científico, num momento em que o programa de pósgraduação mudava seu nome, de Biblioteconomia para Ciência da Informação, sendo criado o curso de doutorado, e vindo logo depois o nome da própria escola.

Tal fato se confirma com a análise global da vinculação institucional dos autores de todos os artigos, apresentada a seguir, na TABELA 1:

TABELA 1 - Vinculação institucional dos autores que publicaram na PCI

\begin{tabular}{l|c}
\hline \multicolumn{1}{c|}{$\begin{array}{c}\text { Instituição de vínculo dos } \\
\text { autores }\end{array}$} & $\begin{array}{c}\text { Total de } \\
\text { produção }\end{array}$ \\
\hline UFMG & 165 \\
USP & 35 \\
Uff & 25 \\
UFSC & 19 \\
Fiocruz & 17 \\
UnB & 17 \\
UEL & 17 \\
UFPb & 16 \\
UFPR & 16 \\
Ibict & 11 \\
Unesp & 11 \\
\hline
\end{tabular}

Fonte Dados da pesquisa. 
Os dados apresentados acima evidenciam o peso fundamental da produção da própria UFMG, representando $29,94 \%$ do total de autores. Em relação à REB, onde este número foi de 37,69\% (ARAúJO et al, 2010), houve uma queda considerável, aumentando a participação de autores de outras instituições. Logo a seguir vêm a Universidade de São Paulo (USP), Universidade Federal Fluminense (Uff) e Universidade Federal de Santa Catatina (UFSC). No estudo da REB (ARAÚJO et al, 2010), as universidades com maior freqüência foram a Universidade Federal da Paraíba (UFPb), a USP e a Universidade de Brasília (UnB). No estudo da PCI, foram encontradas ainda outras 73 instituições brasileiras e, ainda, 14 instituições estrangeiras, de países variados como França, México, Estados Unidos, Espanha e Canadá. Entre as instituições a que pertencem o maior número de autores, destacam-se as universidades onde existia ou veio a existir programas de pós-graduação em Ciência da Informação, seguidas de universidades ou faculdades onde existia e/ou existe curso de graduação em Biblioteconomia, e depois institutos de pesquisa, bibliotecas, órgãos governamentais e empresas.

\subsection{Sobre as temáticas dos artigos}

Para a análise das temáticas dos artigos publicados em PCI, optouse pela utilização das palavras-chave indicadas pelos próprios autores e publicadas nas revistas. Como não existe instrumento de controle terminológico das palavras-chave, observou-se uma variação imensa na maneira de expressar determinados conceitos da área. Quando foi possível, procedeu-se a uma padronização terminológica - mas em alguns casos não foi possível realizar essa tarefa sem comprometer a consistência do trabalho analítico realizado. A gigantesca dispersão dos termos levantados, bem como a natureza diferente das categorias usadas como palavras-chave, impede uma análise aprofundada que possibilite uma real identificação temática dos artigos. Contudo, é possível visualizar um quadro sugestivo de questões que foram historicamente privilegiadas nos primeiros 15 anos da revista. A seguir, são apresentados os termos mais freqüentes no conjunto de artigos analisados:

TABELA 2 - Palavras-chave mais frequentes nos artigos publicados na PCI

\begin{tabular}{l|c}
\hline \multicolumn{1}{c|}{ Palavra-chave } & Frequência \\
\hline Ciência da informação & 27 \\
Informação & 21 \\
Gestão do conhecimento & 15 \\
Análise de redes sociais & 14 \\
Comunicação científica & 11 \\
Bibliometria & 10 \\
Internet & 9 \\
Biblioteconomia & 8 \\
\hline
\end{tabular}




\begin{tabular}{l|l}
\hline Fonte de informação & 8 \\
Conhecimento & 8 \\
Profissional da informação & 7 \\
Ontologias & 7 \\
Gestão da informação & 7 \\
Sociedade da informação & 6 \\
Produção científica & 6 \\
Bibliotecário & 6 \\
Epistemologia & 5 \\
Tecnologia & 5 \\
Biblioteca & 5 \\
Periódico & 5 \\
Análise de citação & 5 \\
Tecnologia da informação & 5 \\
\hline
\end{tabular}

Alguns termos aparecem com alta incidência por motivos óbvios, tais como "Ciência da informação" e "Informação", relacionados tanto com o campo de conhecimento geral como com o objeto de estudo da área. Outros marcam subáreas mais específicas de estudo ou campos de aplicação, tais como a "Gestão do conhecimento", a "Comunicação científica", a "Bibliometria" e as "Ontologias". A dimensão tecnológica aparece expressa em termos como "Internet", "Tecnologia" e "Tecnologia da informação", mas também as dimensões teóricas do estudo da informação e suas implicações sociais estão presentes, como atestam os termos "Análise de redes sociais", "Profissional da informação", "Sociedade da informação" e "Epistemologia". A Biblioteconomia tem um destaque considerável, com os termos "Bibliotecário" e "Biblioteca" também estando entre os mais presentes.

Outras subáreas de pesquisa, tais como "Organização da informação", "Usuários da informação", "Competência informacional", "Memória" e "Patrimônio" também aparecem com incidência importante, porém às vezes diluída em mais de um termo utilizado para expressá-las. É alto também o índice de termos relativos a serviços ou instrumentos específicos, tais como "Disseminação", "Arquivo", "Catálogos" ou "Mediação", bem como a termos que representam entidades singulares ("Brasil", "Google", "Fundação Oswaldo Cruz", entre outras). De toda forma, o material encontrado é de uma riqueza imensa e mereceria ainda estudos posteriores para revelar possíveis relações entre esses termos, inclusive com a possibilidade de se explorar os casos de co-ocorrência. 


\subsection{Sobre as referências encontradas nos artigos}

A análise seguinte recaiu sobre as referências presentes nos artigos analisados. Foram encontradas um total de 4965 referências e 4130 autores diferentes, sendo alguns deles autores institucionais. Destes 4130 autores citados nas referências, 3205 receberam apenas uma citação, perfazendo um total de $77,60 \%$ dos autores citados e sendo responsáveis por $50,72 \%$ do total de referências. Com duas citações, foram encontrados 489 autores $(11,84 \%)$ e, com três citações, 206 autores $(4,98 \%)$. Somando-se então o contingente de autores que receberam até três citações, tem-se um total de 3900 autores, que juntos receberam 4801 citações, o que equivale a $75,98 \%$ do total das referências encontradas.

No campo intermediário, encontram-se 207 autores que receberam entre quatro e 11 citações. Estes autores se distribuem da seguinte forma: 80 autores com quatro citações, 44 com cinco citações, 19 com seis citações, 21 com sete citações, 18 com oito citações, oito com nove citações, oito com dez citações e nove autores com 11 citações. No total, estes autores receberam 1196 citações, o que equivale a 18,93 \% do total das referências encontradas.

Por fim, foram encontrados 23 autores que receberam mais de 12 citações. Juntos, eles receberam um total de 321 citações, equivalentes a $5,08 \%$ do total de citações encontradas.

Os 23 autores mais citados são apresentados a seguir, na TABELA 3.

TABELA 3 - Autores mais citados pelos artigos publicados na PCI

\begin{tabular}{l|c}
\hline \multicolumn{1}{c|}{ Autor } & Citações \\
\hline ECO, U. & 23 \\
CHOO, C.W. & 20 \\
LANCASTER, F.W. & 16 \\
MUELLER, S.P.M. & 16 \\
DRUCKER, P. & 15 \\
CAPURRO, R. & 15 \\
NONAKA, I. & 14 \\
DAVENPORT, T.H. & 14 \\
HABERMAS, J. & 14 \\
CAMPELLO, B.S. & 14 \\
FIGUEIREDO, N. & 13 \\
CASTELLS, M. & 13 \\
CUNHA, M.B. & 13 \\
VIEIRA, A.S. & 13 \\
BOURDIEU, P. & 12 \\
DERVIN, B. & 12 \\
\hline
\end{tabular}




\begin{tabular}{l|c}
\hline FREIRE, I.M. & 12 \\
WILSON, T.D. & 12 \\
MARTELETO, R.M. & 12 \\
MORIN, E. & 12 \\
LARA, M.L.G. & 12 \\
DEMO, P. & 12 \\
BARRETO, A.A. & 12 \\
Autores entre 4 e 11 citações & 1196 \\
Autores com três citações & 618 \\
Autores com duas citações & 978 \\
Autores com uma citação & 3205 \\
\hline \multicolumn{1}{c|}{ TOTAL } & $\mathbf{6 3 1 8}$ \\
\hline
\end{tabular}

Os dados evidenciam, em primeiro lugar, uma gigantesca dispersão nas citações, de forma que entre o núcleo de autores mais citados há pouca concentração das citações. Mais de três quartos de todas as citações foram recebidas por autores que obtiveram até três citações. 0 núcleo de autores com mais de 12 citações obteve apenas $5 \%$ do total de citações.

Entre os autores mais citados, observa-se um equilíbrio entre autores brasileiros e estrangeiros. Os estrangeiros, contudo, são em grande parte autores consagrados de diferentes disciplinas do campo das ciências sociais, como a Semiótica (Eco), a Administração (Drucker, Davenport) e a Sociologia (Habermas, Castells, Bourdieu, Morin), embora autores pertencentes ao campo da Ciência da Informação se destaquem, como atesta a presença, nesta lista, de Choo, Lancaster, Capurro, Dervin e Wilson. Entre os autores brasileiros mais citados, apenas Demo não é diretamente ligado ao campo da Ciência da Informação. Contudo, tanto este autor quanto os estrangeiros citados mas não pertencentes ao campo da Ciência da Informação são autores que trabalham com temáticas muito próximas ao campo, tais como as contradições da sociedade da informação, a gestão do conhecimento nas organizações, os produtos e a indústria da informação, entre outros.

É importante destacar também que alguns dos autores que aparecem nesta lista também figuraram na lista de autores mais citados na extinta Revista da Escola de Biblioteconomia da UFMG. São eles: Lancaster, Cunha, Figueiredo e Vieira (ARAÚJO et al, 2010).

Como forma de complementação dos dados sobre os autores mais citados, buscou-se verificar também as obras mais citadas. Neste caso, o número total foi de 4965 referências. Destas, o impressionante valor de 4665 corresponde ao total de obras que foram citadas uma única vez - ou seja, apenas 300 obras receberam pelo menos mais de uma citação.

A obra mais citada foi "Criação de conhecimento na empresa: como as empresas japonesas geram a dinâmica da inovação" (17 citações), vindo, a seguir, "A organização do conhecimento: como as organizações 
usam a informação para criar significado, construir conhecimento e tomar decisões" (11 citações), "A sociedade em rede" (10 citações) e "A comunicação científica" (10 citações). O baixo grau de concentração das citações a trabalhos científicos específicos mostra que, mesmo no caso de autores que receberam muitas citações, há muitos trabalhos que receberam apenas uma ou duas citações, aumentando o grau geral de dispersão da literatura citada nas referências de PCI.

Outro dado coletado na pesquisa diz respeito ao idioma das referências citadas nos artigos. Os dados são apresentados a seguir, na TABELA 4:

TABELA 4 - Idioma das referências encontradas na PCI

\begin{tabular}{cc}
\hline Idioma & Freqüência \\
\hline Português & 2799 \\
Inglês & 1830 \\
Francês & 193 \\
Espanhol & 136 \\
Outros & 7 \\
Total & $\mathbf{4 9 6 5}$
\end{tabular}

O idioma com maior percentual é o português, atingindo $56,37 \%$ do total, vindo, a seguir, o inglês, com $36,85 \%$. Juntas, estes dois idiomas respondem por $93,23 \%$ do total das citações. É curioso ressaltar que, na comparação com o estudo da REB, verifica-se na PCI uma inversão. No estudo da REB foi verificado que o idioma mais presente foi o inglês, com $54,66 \%$ do total, vindo a seguir o português com 39,12\% (ARAÚJO et al, 2010). Vários podem ser os fatores explicativos deste fato, e nos limites deste estudo não cabe a problematização desta questão, mas os dados evidenciados dos autores e obras mais citados parecem indicar que o fato de muitos trabalhos terem sido traduzidos para o português ajuda a entender os valores encontrados. Ao mesmo tempo, em comparação com o estudo da REB, é fato que aumentou o volume da produção científica nacional nas últimas décadas, fazendo da literatura nacional uma fonte também cada vez mais consultada pelos pesquisadores do campo.

Como forma de complementar os resultados encontrados e proporcionar mais elementos para uma possível interpretação destes dados, foi realizada uma análise do país de publicação das referências. Das 4965 referências encontradas, 2335 são de trabalhos publicados no Brasil, com 430 nos Estados Unidos, 136 da França, 97 da Inglaterra, 56 de Portugal. Tais dados devem ser analisados com cautela, contudo, uma vez que não foi possível determinar a procedência de 1710 referências. Ressalte-se, contudo, que foram encontradas referências provenientes de 31 países diferentes.

Também fez parte do estudo uma análise da tipologia dos documentos citados nas referências. Para tanto, foram consideradas seis categorias, sendo que aqueles que não se encaixavam em alguma delas 
foram classificados como "outros" (que consistiu na sétima categoria). Os dados encontrados estão na TABELA 5:

TABELA 5 - Tipologia das referências encontradas na PCI

\begin{tabular}{cc}
\hline Tipologia & Frequência \\
\hline Livro & 2203 \\
Artigo de periódico científico & 1732 \\
Documento disponível na internet & 442 \\
Trabalho apresentado em congresso & 268 \\
Dissertação ou tese & 178 \\
Outro & 142 \\
Total & $\mathbf{4 9 6 5}$
\end{tabular}

Os livros e artigos publicados em periódicos científicos representam uma imensa proporção do material citado nas referências: juntos, perfazem $79,25 \%$ de tudo o que foi citado pelos artigos publicados na PCI - dado muito próximo ao que foi encontrado no estudo da REB, em que a soma dos dois tipos de documentos perfazia $84,29 \%$ do total (ARAújO et al, 2010). Tal fato evidencia uma produção mais centrada nos produtos mais típicos e usuais da atividade científica, sendo que com a predominância de livros relaciona-se a uma característica típica das ciências humanas e sociais. Há pouca incursão por materiais alternativos, embora se verifique o crescimento da utilização de documentos disponíveis em meio digital, perfazendo $8,90 \%$ do total (esse dado não estava disponível no estudo da REB, o que inviabiliza uma comparação), e algum destaque para os trabalhos publicados em anais de eventos científicos, com 5, 39\% - no estudo da REB, esse valor foi muito próximo, de 5,56\%. Na categoria "outros" verificou-se uma grande variedade de tipos documentais tais como normas técnicas, jornais, anotações de aula, programas de televisão, entre outros.

Outro dado analisado a partir das referências dos artigos foi a data de publicação. A análise foi realizada contabilizando-se ano a ano e, depois, agrupada considerando-se as décadas em que os trabalhos foram publicados. Os resultados estão na TABELA 6:

TABELA 7 - Data das referências

\begin{tabular}{c|c|c}
\hline Período & Frequiência & $\begin{array}{c}\text { Total } \\
\text { acumulado }\end{array}$ \\
\hline Antes de 1900 & 3 & 3 \\
1900 a 1909 & 0 & 3 \\
1910 a 1919 & 2 & 5 \\
1920 a 1929 & 2 & 7 \\
1930 a 1939 & 11 & 18 \\
1940 a 1949 & 8 & 26 \\
1950 a 1959 & 29 & 55 \\
1960 a 1969 & 87 & 142
\end{tabular}




\begin{tabular}{ccc}
1970 a 1979 & 286 & 428 \\
1980 a 1989 & 620 & 1048 \\
1990 a 1999 & 2071 & 3119 \\
2000 a 2010 & 1764 & 4883 \\
Sem indicação & 82 & 4965 \\
Total & $\mathbf{4 9 6 5}$ & - \\
\hline
\end{tabular}

Como era de se esperar, a freqüência de trabalhos publicados nos anos mais recentes destacam-se em volume, com a quantidade de trabalhos publicados na última década respondendo por 35,52\% do total. A se considerar as duas últimas décadas, esse valor atinge $77,24 \%$. Chama a atenção, contudo, a existência ainda de considerável quantidade de referências publicadas muito tempo antes, em alguns casos até mesmo 80 anos antes - e são tanto casos de trabalhos científicos quanto documentos históricos. Muitas vezes são citados trabalhos dos autores pioneiros em algumas temáticas. Trabalhos publicados até 1959 chegam ao importante índice de $1,10 \%$, bastante menor, porém, do que os $5,56 \%$ encontrados na pesquisa sobre a REB (ARAÚJO et al, 2010). Ressalte-se ainda um alto volume de referências (82) sem indicação de data.

\subsection{Sobre os periódicos citados}

A análise seguinte recaiu sobre os periódicos citados nas referências dos artigos publicados na PCI. Os artigos científicos citados foram publicados em 372 diferentes periódicos, dos quais 164 periódicos brasileiros e 208 periódicos estrangeiros. Entre os brasileiros, 102 periódicos receberam apenas uma citação; entre os estrangeiros, foram 122 nessa situação. Os seis periódicos nacionais que mais receberam citações são apresentados TABELA 8.

TABELA 8 -Periódicos brasileiros mais citados nas referências dos artigos publicados na PCI

\begin{tabular}{lc}
\hline & Total \\
\hline Ciência da Informação & 266 \\
Perspectivas em Ciência da Informação & 55 \\
Revista da Escola de Biblioteconomia da UFMG & 34 \\
Datagramazero & 34 \\
Transinformação & 32 \\
Revista de Biblioteconomia de Brasília & 32 \\
\hline
\end{tabular}

Fonte: Dados da pesquisa. 
Já os seis periódicos estrangeiros que mais receberam citações são apresentados TABELA 9.

TABELA 9 -Periódicos estrangeiros mais citados nas referências dos artigos publicados na PCI

\begin{tabular}{l|c}
\hline & Total \\
\hline Journal of Documentation & 34 \\
Scientometrics & 33 \\
Information Processing \& Management & 27 \\
Journal of Information Science & 22 \\
Annual Review of Information Science and Technology & 22 \\
Journal of American Society of Information Science and Technology & 21 \\
\hline
\end{tabular}

Fonte: Dados da pesquisa.

O periódico mais citado, entre todos, é Ciência da Informação, com 266 citações. A seguir, vem a própria revista, com 55 citações. As demais revistas mais citadas, tanto nacionais quanto estrangeiras, alcançaram valores muito próximos, entre 34 e 21 citações. Percebe-se, contudo, um volume um pouco maior de citações a periódicos nacionais $(54,30 \%)$ do que estrangeiros $(45,69 \%)$. A verificação das nacionalidades evidenciou que a maior parte das citações a periódicos estrangeiros é de periódicos provenientes dos Estados Unidos (437), vindo a seguir o Reino Unido (65), Hungria (33), Espanha (32) e França (20), aparecendo ainda outros 18 países.

\section{Considerações finais}

Os resultados apresentados neste artigo confirmam, mais uma vez, o potencial que os estudos bibliométricos têm para fornecer indicadores da evolução de uma área por meio do estudo de um periódico específico. Por meio destes estudos se pode verificar quem foram os autores mais consultados, os países e institutos de pesquisa mais influentes, os periódicos mais destacados.

No que tange especificamente ao conhecimento sobre a revista Perspectivas em Ciência da Informação, a pesquisa apresentada permitiu comprovar o compromisso do periódico com a diversidade, por meio da preocupação em ser espaço de veiculação dos conhecimentos produzidos nas variadas subáreas da Ciência da Informação, bem como de reflexões e pesquisas sobre a informação oriundas de diferentes centros e instituições, apoiadas também em trabalhos de uma gama diversa de autores.

\section{Referências}

ARAÚJO, Carlos Alberto Ávila. Bibliometria: evolução histórica e questões atuais. Em Questão, Porto Alegre, v. 12, n.1, p. 11-32, jan./jun. 2006. 
ARAÚJO, Carlos Alberto Ávila et al. Um retrato da Revista de Escola de Biblioteconomia da UFMG. Perspectivas em Ciência da Informação, v.Especial, p. 131-151, 2010.

BRAMBILLA, Sônia Domingues Santos; VANZ, Samile Andréa de Souza; STUMPF, Ida Regina. Mapeamento de um artigo produzido na UFRGS: razões das citações recebidas. Encontros Bibli: Revista Eletrônica de Biblioteconomia e Ciência da Informação, Florianópolis, n. esp., $1^{0}$ sem. 2006, p. 195-208.

COSTA, Josiane; VANZ, Samile. A produção intelectual em ciência da informação: análise de citações do DCI/UFRGS de 2000 a 2008. Em Questão, Porto Alegre, v. 16, n.1, p, 79-93, jan./jun. 2010. LEIPZIG, F. T. Brazilian Library Literaure. International Library Review, London, v. 8, p. 379-395, 1976.

FIGUEIREDO, Nice. Tópicos modernos em Bibliometria. Brasília: Associação dos Bibliotecários do Distrito Federal, 1977.

FORESTI, Nóris. Estudo da contribuição das revistas brasileiras de biblioteconomia e ciência da informação enquanto fonte de referência para a pesquisa. Brasília: Depto. de Biblioteconomia da UnB, 1989 (dissertação de mestrado).

FORESTI, N. A B.; MARTINS, M. S. M. Revistas brasileiras de biblioteconomia, documentação e Ciência da Informação: produtividade de autores no período de 1980 a 1985. R. Esc. Bibliotecon. UFMG, Belo Horizonte, v . 16, ,n. 1, p. 54-71, mar. 1987.

MACHADO, Raymundo das Neves. Análise cientométrica dos estudos bibliométricos publicados em periódicos da área de biblioteconomia e ciência da informação (1990-2005). Perspectivas em Ciência da Informação, Belo Horizonte, v. 12, n. 3, p. 2-20, set./dez. 2007

MAIA, Maria de Fátima S.; CAREGNATO, Sônia Elisa. Co-autoria como indicador de redes de colaboração científica. Perspectivas em Ciência da Informação, v.13, n.2, p. 18-31, maio/ago. 2008.

MIRANDA, A. Revistas especializadas brasileiras de biblioteconomia e ciência da informação, com ênfase na experiência da ABDF. Boletim ABDF, Nova Série. Brasília, v. 4, n. 4, p. 30-42, out./dez. 1981.

RODRIGUES, Maria da Paz. Estudo das citações constantes das dissertações de mestrado em ciência da informação do IBICT/UFRJ. Dissertação (Mestrado em Ciência da Informação). Curso de PósGraduação em Ciência da Informação, Ibict/UFRJ, Rio de Janeiro, 1981.

ROUSSEAU, Ronald. Indicadores bibliométricos e econométricos para a avaliação de instituições científicas. Ciência da Informação, Brasília, v. 27, n. 2, p. 149-158, maio/ago. 1998.

VANTI, Nadia Aurora. Da bibliometria à webometria: uma exploração conceitual dos mecanismos utilizados para medir o registro da informação e a difusão do conhecimento. Ciência da Informação, Brasília, v. 31, n. 2, p. 152-162, maio/ago. 2002. 
Análise dos quinze anos do periódico Perspectivas em Ciência da Informação
Carlos Alberto Ávila Araújo; Marlene Oliveira Teixeira de Melo 